\title{
ANÁLISE DAS VARIÁVEIS CULTURAIS DA GESTÃO MUNICIPAL SOB A ÓPTICA DA NOVA GESTÃO PÚBLICA
}

\author{
Tatiana Souto Maior de Oliveira ${ }^{1}$ \\ Denis Alcides Rezende 2
}

\begin{abstract}
Resumo: A introdução de novos formatos de gestão municipal, calcados em práticas e valores opostos à cultura instaurada em Prefeituras, pode acarretar o insucesso de suas ações. 0 objetivo central desta pesquisa é analisar quais as variáveis culturais existentes nas Prefeituras, que podem influenciar a gestão municipal delas em relação aos preceitos da teoria da nova gestão pública (New Public Management - NPM). Com base em pesquisa bibliográfica, foram destacadas variáveis culturais (poder, personalismo, determinismo e adaptabilidade) e variáveis da nova gestão pública (reestruturação, práticas privadas e participação social), que formalizaram o protocolo da pesquisa. Por meio de um estudo de multicasos, abrangendo três Prefeituras da região metropolitana de Curitiba, e com a triangulação das ferramentas de coleta de dados (questionário, entrevista e observação assistemática), foi possível a identificação dessas variáveis nas Prefeituras e 0 aprofundamento das relações existentes entre elas. A conclusão reitera que a identificação e a construção de um mapa de variáveis culturais podem possibilitar, aos gestores públicos, um melhor controle e aproveitamento de suas ações.
\end{abstract}

Palavras chaves: Gestão municipal. Cultura brasileira. Cultura organizacional.

\section{INTRODUÇÃO}

O advento da globalização e a conseqüente alteração na dinâmica do mercado mundial têm impactado diretamente o cotidiano dos países, que se vêem à mercê das variações macroeconômicas. $\mathrm{Na}$ maioria dos casos, principalmente nos países periféricos, essas alterações agravam as deficiências existentes, provocando o surgimento de novas demandas sociais. Diante desse cenário turbulento e delicado, o Estado começa a perceber que o modelo atual de gestão não está preparado para atender a nova realidade da sociedade. Inicia-se um processo de reestruturação do Estado, que tem como base fundamental o aprimoramento da gestão, com a finalidade de torná-lo uma organização mais eficiente e eficaz para a sociedade.

As alterações, que se impõem ao Estado, sejam elas de ordem federal, estadual e, sobretudo, municipal, geram, além de uma mudança no formato de gestão, o desafio de uma mudança cultural. Isso significa que novos valores são introduzidos em uma organização, que tem em suas raízes a cultura administrativa de colonizadores, a qual se mostra fortemente relegada aos modelos burocráticos, patrimonialistas e clientelistas (PEREIRA, 1997).

Compreende-se que a inserção de uma nova cultura administrativa pode impactar 0 andamento e o sucesso dessa iniciativa (HERNANDEZ; CALDAS, 2001) e que as alterações, que vêm ocorrendo, alteram muitas práticas institucionalizadas. Com base nesse dado, o objetivo desta pesquisa é identificar e analisar quais variáveis culturais existentes nas Prefeituras podem influenciar a

\footnotetext{
1 Programa de Mestrado em Gestão Urbana, PUCPR, Curitiba, Paraná. E-mail: tatianasoutomaior@ gmail.com

2 Programa de Mestrado em Gestão Urbana, PUCPR e Curso de Graduação em Administração da FAE Business School, Curitiba, Paraná E-mail: denis.rezende@ @ucpr.br;
} 
sua gestão municipal em relação aos preceitos da teoria da nova gestão pública (New Public Management - NPM). 0 intuito desta pesquisa, então, é elaborar um mapa com as variáveis identificadas, possibilitando o uso desse material, pelos gestores municipais, na condução das mudanças administrativas necessárias nas Prefeituras. O mapa pode permitir uma maior efetividade da gestão municipal, fazendo com que essa gestão atinja seus objetivos mais efetivamente. 0 mapa é oriundo de um estudo de caso em três Prefeituras.

Para realização deste trabalho, primeiramente elabora-se um aprofundamento teórico nas temáticas de gestão municipal, gestão urbana, nova gestão pública, cultura, cultura brasileira e cultura organizacional, possibilitando, assim, um posicionamento teórico frente às questões a serem analisadas. Na seqüência, detalha-se a metodologia utilizada na pesquisa, bem como sua prática (aplicação). Como etapa final, são apresentados os resultados das análises das Prefeituras estudadas.

O mapa de variáveis culturais, identificadas e analisadas, permite um aprofundamento no estudo das questões culturais, possibilitando, na seqüência, um trabalho similar no âmbito da sociedade civil. Em outras palavras, o mapa permite ampliar a análise para 0 ambiente externo das Prefeituras, o qual, da mesma forma que essas, tem sofrido alterações quanto ao seu papel na gestão municipal. 0 resultado da pesquisa, em forma de mapa de variáveis, abre caminhos para a troca de experiências com outras Prefeituras, estendendo-se, assim, os benefícios a elas. O mapeamento das variáveis culturais e seu uso efetivo na gestão municipal também podem viabilizar um melhor desempenho dos objetivos, das estratégias e das ações das Prefeituras.

\subsection{PROBLEMA E JUSTIFICATIVA}

As questões da gestão municipal e da administração local têm sido evidenciadas principalmente pelo fato de que as alterações sofridas pela administração pública direcionaram novas responsabilidades aos municípios, por meio da descentralização de atividades que eram concentradas no âmbito federal. As novas atribuições do município, como as elaborações do plano plurianual municipal, do plano diretor da cidade e do planejamento estratégico, fazem emergir a profissionalização dos órgãos públicos e a introdução de uma nova postura administrativa (PEREIRA, 1997).

A nova gestão pública é baseada em preceitos administrativos oriundos das organizações privadas, permitindo uma flexibilização da máquina administrativa e possibilitando 0 atendimento das demandas impostas ao Estado (BRASIL, 1995; PEREIRA, 1997). O dilema concentra-se na ocorrência de que um ou mais indivíduos inserem novas idéias na organização, em oposição aos pressupostos e práticas, forçando os membros destas a reconsiderarem suas tradições (OSBORNE; GAEBLER, 1998; JONES; THOMPSON, 2002).

O novo formato cultural de gestão pública depara-se com a quebra de ranços culturais da época colonial, como o clientelismo e o patrimonialismo, o que pode dificultar a mudança da cultura nas organizações públicas. Percebe-se, de um lado, práticas gerenciais herdadas do passado e calcadas em traços culturais básicos da cultura brasileira e, do outro, a importação de novos padrões oriundos de empresas privadas (FREITAS, 1991).

Assim, para que seja possível a alteração da cultura organizacional nas Prefeituras, torna-se fundamental o conhecimento das variáveis culturais existentes, com a finalidade de garantir a eficácia do novo formato de gestão (GOHN, 2001). Esse trabalho deve ser desenvolvido em paralelo às mudanças gerenciais e legais que acontecem na administração pública (BRASIL, 1995). Ao se atentar para as questões culturais, nos processos de reestruturação organizacional, é possível corrigir alguns erros cometidos anteriormente por especialistas, na condução dessas mudanças, reconhecendo-se que a profissionalização da administração pública, além de técnica, deve ser acompanhada de uma compreensão profunda, não superficial, da cultura e de seus aspectos diversos (AMATO, 1971). 
Reiterando a justificativa apresentada, é importante, nesse ponto, conceber que 0 conhecimento e a possibilidade de se trabalhar as variáveis culturais são vitais para a reestruturação organizacional (FREITAS, 1991), bem como para as alterações que estão ocorrendo em todas as áreas da gestão urbana. Essas variáveis podem funcionar como um complicador ou um aliado na implementação de novas políticas administrativas, relacionando-se também com o desempenho da gestão (BARBOSA, 1996). Em particular, as cidades sofrem um impacto ainda maior desse cenário, uma vez que as alterações, que elas vêm sofrendo, exigem uma mudança radical em suas formas de atuação, no sentido de novas responsabilidades e da capacidade de execução que passam a ser impostas a elas.

\section{REVISÃO DA LITERATURA}

\subsection{CENÁRIO URBANO}

Durante muito tempo, no que tange à vida na era artesanal, as comunidades viviam isoladas, distantes umas das outras. Elas eram formadas basicamente de aglomerados familiares, que se encontravam esporadicamente em busca de possíveis trocas mercantis. Desse modo, percebe-se, com essas asserções, que as cidades surgiram, desde seus primórdios, em função de questões econômicas, tornando-se um lugar de articulação dos interesses econômicos, um lugar para negócios (BARREIRA, 2003).

Acompanha-se, atualmente, um crescente desenvolvimento e interesse pelas cidades, em específico, pelas suas potencialidades econômicas. Esses locais tornam-se foco de atenções, devido a suas capacidades econômicas e às potencialidades de resolução das demandas frente as suas dimensões diminutas (DOWBOR, 1999). Devido à importância das cidades e ao crescente processo de urbanização percebido em toda a sociedade, somado ao advento da globalização, gera-se um novo cenário às cidades. Essas, além de gerir os processos de sua dinâmica interna, vêem-se frente à necessidade de tratar de novas questões, que vêm deteriorando a dinâmica delas (LOPES, 1998). Nesse cenário, é atribuído um novo papel estratégico às cidades, que permite a sua manutenção no contexto global (CARVALHO, 2000). As cidades perdem o seu caráter estático e controlável, inserindose em um contexto onde o tempo e o espaço perdem significância (CASTELLS, 1999). A cidade globalizada é, hoje, um ambiente dissociado da localidade e, ao mesmo tempo, extremamente dependente de seus aspectos significativos, culturais, sociais e econômicos. Esse tipo de cidade procura se adaptar e sobreviver em um contexto onde as influências externas são constantes e determinantes (DOWBOR, 1999; BARREIRA, 2003).

\subsubsection{A gestão da nova cidade}

A alteração do conceito de cidades causa impacto, diretamente, na forma como essas vêm sendo geridas. Comandar uma cidade, influenciada por alterações macroeconômicas, que seja globalizada e informacional, onde as mazelas sociais se proliferam de forma demasiada, não é 0 mesmo que gerir uma cidade espacialmente controlada (DOWBOR, 1999). A gestão do município, no atual cenário, deve ser entendida como um processo participatório, através do qual, com base em recursos e instrumentos de administração, possibilite a melhoria de qualidade dos serviços urbanos e propicie melhores condições de vida à população (REZENDE, 2004). Esse é um processo em que 0 ato de gerir a coisa pública, localizado tradicionalmente no Estado (AMATO, 1971), migra da esfera exclusivamente estatal para a esfera democrática. 
Os conceitos de gestão municipal e gestão urbana se complementam e se fortalecem com os fundamentos da administração científica, considerando o município como um organismo dinâmico e complexo, o qual é caracterizado por diversidades, contrastes, interesses múltiplos e divergentes. A nova gestão da cidade é entendida como o conjunto de recursos e instrumentos da administração pública, ampliados na cidade como um todo, propiciando melhores condições de vida e participação à sociedade. Nesse contexto amplo, a gestão municipal refere-se ao conjunto de ferramentas aplicadas à administração do município, as quais sejam capazes de colaborar com o alcance dos objetivos maiores da gestão da cidade (REZENDE; CASTOR, 2005).

\subsubsection{Uma nova gestão pública}

A nova gestão pública, em sentido macro, parte da revisão do papel do Estado e do desenvolvimento democrático. Há que se repensar a dinâmica da realidade na qual o Estado está inserido. Não há como pensar em ações governamentais estanques.

A nova gestão pública (NPM) é compreendida como a profissionalização da administração pública, baseada nas melhores práticas do mercado privado, com a ressalva de que há a necessidade de se realizarem adaptações (PEREIRA, 1997). Na maioria das experiências, existe um eixo que é nomeado de estrutural, em que são realçados os principais pontos de mudança. Entre eles, destacamse: profissionalização da alta burocracia, transparência e responsabilização democrática na administração pública, desconcentração organizacional, controle de resultados por meio de indicadores e adoção de novo desenho organizacional para atividades não exclusivas (MARINI, 2002). As características da nova gestão pública reúnem-se nas seguintes variáveis:

\section{a) Quanto à reestruturação organizacional e reengenharia}

Quanto à descentralização na área pública, percebe-se o processo de transferência de atividades e responsabilidades, anteriormente concentradas na administração central (no caso do Brasil, no federal), para outros níveis do governo, estados e municípios, bem como para a sociedade civil (OSBORNE; GAEBLER, 1998; PEREIRA, 1997).

Quanto ao alinhamento, ele se constitui na identificação das atividades que são produtivas, que devem ser fortalecidas e que devem ser abandonadas (DRUCKER, 1999). A necessidade de um novo Estado, mais flexível e conseqüentemente mais preparado para lidar com as variações do contexto atual, coloca como ponto principal, na estratégia da nova gestão pública, 0 processo de descentralização administrativa e operacional (OSBORNE; GAEBLER, 1998; MARINI, 2002).

Quanto à reengenharia, afirma-se que é um processo de reestruturação organizacional participativa, que normalmente envolve 0 uso de novas técnicas de alinhamento organizacional e 0 uso inteligente da tecnologia da informação. Ela estabelece o foco nos processos organizacionais e não mais em funções (JONES; THOMPSON, 2002).

\section{b) Quanto às práticas privadas}

As principais práticas ou conceitos, que têm sido inseridos na gestão pública, contemplam o foco no cliente, na tecnologia da informação, na administração por resultados, no empreendedorismo, no planejamento estratégico e na parceria público-privado (OSBORNE; GAEBLER, 1998; MARINI, 2002).

Quanto ao foco no cliente, a maioria das reestruturações ocorridas tem como realce a centralização dos esforços no público-alvo da organização pública, isto é, no cidadão. Essas 
reestruturações, então, têm a mesma visão - de concentrar a atenção e os esforços para atender às necessidades dos clientes (OSBORNE; GAEBLER, 1998).

No que tange à tecnologia da informação, destaca-se o uso de ferramentas tecnológicas, que permitem uma maior eficiência do Estado e que possibilitam o livre fluxo de informações entre o público e o privado e entre novos atores da sociedade civil (FERGUSON, 2002).

A administração por resultados - outra prática inserida na gestão pública - busca alterar 0 formato de avaliação existente nas organizações públicas, o qual é baseado no controle excessivo de entradas, de recursos, de regras e de procedimentos (OSBORNE; GAEBLER, 1998).

No tocante ao empreendedorismo, há a introdução, nas organizações públicas, de uma administração extremamente flexível, ágil e criativa, que objetiva conseguir encontrar alternativas viáveis para 0 atendimento das demandas sociais. Trata-se, nesse sentido, de encontrar novas formas de ação, que possibilitem o alcance dos objetivos em um cenário com a crescente estagnação das receitas públicas e com o crescimento das demandas (OSBORNE; GAEBLER, 1998).

O planejamento estratégico, por sua vez, é introduzido na organização pública de forma a auxiliar os tradicionais instrumentos de planejamento urbano. Busca-se, no planejamento estratégico, a capacidade de planejar o futuro incerto e controlar os resultados desse planejamento (PFEIFFER, 2000).

A criação de parcerias, no caso a caracterizada como público-privado, refere-se ao processo de reinvenção do Estado, que tem como um de seus pilares a concentração das ações do Estado em atividades consideradas "nobres", como a segurança e o planejamento (BRASIL, 1995).

\section{c) Participação social}

$\mathrm{Na}$ maioria das experiências da nova gestão pública, percebe-se a tendência ao desenvolvimento de processos participativos, como alternativa do governo na busca de novas opções para solucionar os problemas existentes. Acompanha-se um movimento de colaboração entre cidadãos e o setor público, envolvendo troca de conhecimentos e realização de processo decisório, o que permite, sobretudo, o amadurecimento da sociedade frente às questões públicas.

\subsection{CULTURA ORGANIZACIONAL}

Todos os dias milhares de pessoas, em lugares distintos, acordam, vestem-se, alimentam-se, fazem opções diversas. A cultura, então, é compreendida como conjunto de costumes e regras, que trazem consigo determinados significados, os quais são transmitidos de geração para geração, caracterizando, assim, a forma de agir dos grupos (NELSON; LOUREIRO, 1996; GOHN, 2001). Em seu sentido amplo etnográfico, a cultura é entendida como um todo complexo, que inclui conhecimentos, crenças, arte, moral, leis, costumes e/ou qualquer outra capacidade e outros hábitos adquiridos pelo homem na condição de membro de uma sociedade (LARAIA, 2003).

Para diversos antropólogos e sociólogos, a cultura apresenta-se como um conjunto de significados, organizados em termos de representações e símbolos (FREITAS, 1991), sendo nomeada também como um sistema simbólico (GEERTZ, 1978). A cultura é, desse modo, a soma de todos os progressos do homem e da humanidade, nos domínios, e sob todos os pontos de vista, na medida em que estes contribuem para a realização espiritual do indivíduo e para o próprio progresso do progresso.

\subsubsection{Cultura nas organizações}

As organizações, em sua busca por melhores margens de competitividade e 
conseqüentemente continuidade de seus negócios, cada vez mais têm se preocupado com a composição de sua estrutura e com a uniformidade de suas ações (FLEURY, 1996; HOFSTEDE, 1994).

A cultura organizacional é caracterizada como um conjunto de pressupostos, que um grupo inventa, descobre ou aprende para lidar com problemas de adaptação externa e de integração interna. Esses problemas são válidos e são ensinados a novos membros como formas corretas de percebê-los, pensá-los e senti-los (SCHEIN, 1990; FREITAS, 1991). A cultura, nas organizações, tem sido fator determinante do sucesso ou do fracasso de várias iniciativas administrativas. Destacam-se, principalmente, implementação de novas estratégias, de aquisições, de sociedades e introdução de novas tecnologias (SCHEIN, 1990). Portanto, a cultura serve tanto para a sobrevivência da organização, quanto para a sobrevivência da comunidade.

\subsubsection{Variáveis culturais brasileiras}

Para que se possam identificar as variáveis culturais relevantes na mudança de gestão municipal no Brasil, faz-se necessária uma retrospectiva histórico-cultural, como forma de melhor entendimento das organizações públicas brasileiras. Esse tipo de retrospectiva é importante, visto que as organizações sofrem grande influência da cultura nacional, na qual estão inseridas, e, conseqüentemente, influência de seus fundadores (FREITAS, 1991).

\section{a) Quanto ao poder}

O poder é considerado uma capacidade fundamentada no controle de recursos e estende-se a práticas culturais relacionadas à adesão, à permissão e à persuasão (CLEGG, 1992). O Brasil, desde seu descobrimento, foi submetido à convivência com o poder, como determinante das ações na sociedade, isto é, desde a "descoberta" do Brasil, e sua posse por parte de Portugal, foi instituída uma relação entre poderosos e submissos (AIDAR et al, 2002).

Assim, há provas da formação de uma sociedade com base na divisão entre poderosos e submissos, líderes e liderados, em que essas duas unidades estão extremamente distantes entre si. Frente a essa divisão, por conseguinte, tem-se uma sociedade composta por fortes e fracos, ricos e pobres, patrões e clientes, uns fornecendo aos outros, em uma relação de dependência (DA' MATTA, 1997; AIDAR et al, 2002; BARROS; PRATES, 1996). Essa consciência de posição social fica explícita nos costumeiros ditados nacionais, tais como, "um lugar para cada coisa, cada coisa em seu lugar", "cada macaco no seu galho" (DA' MATTA, 1997). Acompanha-se a proliferação de relações autocráticas e paternalistas na sociedade. Essas relações mantêm a divisão social, como se pode depreender do ditado, comumente utilizado no Brasil, "manda quem pode, obedece quem tem juízo". Esse cenário demonstra uma forte relação de submissão, onde os mais fracos acatam as determinações do nível hierárquico mais alto (AIDAR et al., 2002). A presença de poder, então, faz-se notar quando se depara com a postura do "Sabe quem está falando?", fortemente caracterizada em nossa sociedade (BARBOSA, 1992).

\section{b) Quanto ao personalismo}

Dentro do cenário brasileiro, é uma constante a afirmação de que o relacionamento com as pessoas certas realmente faz a diferença (FAORO, 2000). Em decorrência dessa atitude, comprova-se, na estrutura brasileira, a formação da cultura do favoritismo ou clientelismo, através da qual se consegue um determinado apoio em troca de favores. Esse tipo de ação encontra-se permeando um 
grande número de relações sociais na sociedade brasileira e tem sido marcante, como se comprova por meio da maioria das decisões "burocráticas", que tem como base a rede de relações pessoais existentes (BARBOSA, 1992; FAORO, 2000).

No que tange à administração pública, esta esteve ligada aos interesses dos dominantes locais desde cedo, sendo condicionada por hábitos, interesses e estilos do mundo privado, o qual buscou formatar o espaço público como fonte de privilégios pessoais, grupais e de distribuição de cargos, benesses e prebendas.

\section{c) Quanto ao determinismo}

Após a formação social do Brasil e a sua conseqüente estruturação em classes, comprova-se a cristalização de classes, isto é, uma distinção clara frente à possibilidade de cada indivíduo que as compõem. A premissa de que cada um tem seu lugar, faz com que o conformismo, relativo à situação estabelecida, multiplique-se por todo o Brasil. Esse conformismo é transmitido por meio da família, escola, onde historicamente se ensina que não é educado fazer muitas perguntas, por exemplo (DA' MATTA, 1997).

Esse processo de conformidade aos fatos foi comprovado em pesquisa realizada por Hofstede (1994), em que a questão hierárquica é fortemente aceita pelos brasileiros. Esse autor acrescenta, ainda, que o Brasil é um país com alto nível de incerteza, onde não prevalece a preocupação com 0 futuro, há forte resistência a mudanças e o constante medo do fracasso (HOFSTEDE, 1994; AIDAR et al., 2002). Novamente, é possível citar ditados como "cada macaco no seu galho" e "um lugar para cada coisa, cada coisa em seu lugar" (DA' MATTA, 1997), os quais ilustram essa situação descrita.

\section{d) Quanto à adaptabilidade}

Paradoxalmente, o Brasil é conhecido em âmbito internacional pela sua capacidade de improvisação, ou seja, pelo seu jeitinho. Essa habilidade tem como origem a própria adversidade que 0 brasileiro se defrontou, desde o "descobrimento" do Brasil, o que o fez se adaptar às normas estabelecidas na realidade (BARBOSA, 1992). Assim, o jeitinho, como habilidade de adaptação, está presente nos mais variados cenários da vida social brasileira e é usado como forma de contornar possíveis problemas no dia-a-dia do brasileiro. $O$ jeitinho brasileiro permanece, até hoje, como símbolo da criatividade que os brasileiros têm para resolver problemas, seja na vida pessoal ou na vida profissional (BARBOSA, 1992).

\section{METODOLOGIA DA PESQUISA}

A pesquisa foi realizada por meio de um estudo de multicasos, que é definido como o estudo quantitativo, envolvendo mais de um caso, seguido de uma comparação entre eles (YIN, 1994). A evidência de múltiplos casos é considerada mais consistente e os estudos são caracterizados como mais robustos (KOHN, 1997). Esse tipo de estudo abarca a área temática da cultura na gestão municipal e urbana, inter-relacionada com outras áreas, como administração, arquitetura, sociologia e antropologia, caracterizando, assim, uma pesquisa interdisciplinar (PARDINAS, 1977 apud MARCONI; LAKATOS, 1990). Trata-se de uma pesquisa aplicada e descritiva, com uma abordagem quantitativa e qualitativa, que explora fenômenos com base em diferentes ângulos (ROESCH, 1999).

Foi realizada uma triangulação ou combinação de várias ferramentas de coleta de dados, permitindo uma maior consistência, aprofundamento e confiabilidade da pesquisa (JICK, 1979 apud FLEURY, 1997; KOHN, 1997). O trabalho foi desenvolvido em quatro fases, que permitiram 0 
andamento da pesquisa, de forma estruturada. Inicialmente foi elaborada a revisão da literatura (o referencial teórico), na segunda fase foi feita a preparação para a pesquisa, na terceira fase os esforços se destinaram à aplicação prática da pesquisa e, por fim, realizou-se a documentação da pesquisa.

Para se atingir o objetivo metodológico, foi elaborado um protocolo de pesquisa, com o objetivo de guiar o investigador na realização do estudo de caso, garantido que se mantivesse o foco da pesquisa (YIN, 1994). O protocolo de pesquisa foi dividido em três partes. Na primeira, foram identificadas as variáveis culturais a serem selecionadas (poder, personalismo, determinismo e adaptabilidade), na segunda, as variáveis da nova gestão pública (reestruturação, práticas privadas e participação social) e, finalmente, na terceira parte, a relação entre essas variáveis.

Com base no protocolo de pesquisa, foi elaborado um questionário, utilizando a escala Likert contendo 30 questões. Paralelamente, foi elaborado um roteiro de entrevista. A pesquisa foi realizada em três Prefeituras, localizadas na região metropolitana de Curitiba, com o intuito de identificar e validar as variáveis culturais, permitindo uma melhor análise dos resultados (GIL, 1999). Foram analisados os três gestores das áreas relacionadas, diretamente com o planejamento das Prefeituras. A esses gestores foram aplicadas entrevistas semi-estruturadas. Em paralelo, foram analisados os seus servidores municipais, por meio de questionários. Foi selecionada uma amostra estratificada proporcional, com base nos vários setores das Prefeituras, garantindo o mínimo de influência pessoal e setorial na pesquisa. A amostra foi selecionada aleatoriamente, totalizando 50 questionários, sendo 13 na Prefeitura 1, 19 na Prefeitura 2 e 18 na Prefeitura 3. Complementarmente foram realizadas, durante o processo, observações assistemáticas de todas as pessoas envolvidas direta ou indiretamente nas Prefeituras.

\section{ANÁLISE DAS PREFEITURAS}

\subsection{PERFIL DAS PREFEITURAS}

A Prefeitura 1 é de um município da região metropolitana de Curitiba, criado em 25 de janeiro de 1961, localizado na região Leste do Estado do Paraná, Sul do Brasil. O município possui 16.166 habitantes com representantes de grupos étnicos diversos, com predominância de italianos, portugueses, poloneses, alemães e, mais recentemente, de sulistas e nordestinos. A Prefeitura em questão possui atualmente 520 servidores, divididos em várias sedes.

A Prefeitura 2 é de um município criado em 11 de fevereiro de 1.890 e está situado às margens do Rio Iguaçu. É cortada pela BR-476 - Rodovia do Xisto, via de interligação da Região Sudoeste do país. Está a $27 \mathrm{~km}$ do centro de Curitiba, fazendo parte da região metropolitana de Curitiba. Atualmente, a população vinculada a essa Prefeitura 2 é de 104.284 habitantes, é formada por descendentes dos primeiros habitantes da região (luso brasileiros, índios e negros), por descendentes de imigrantes poloneses, italianos, ucranianos, sírios, alemães, japoneses e por migrantes vindos de outras regiões, atraídos pela industrialização, a partir da década de 70 . A Prefeitura em questão possui atualmente 4.530 servidores, sendo que esses estão distribuídos em distintas sedes.

A Prefeitura 3 é de um município da região metropolitana de Curitiba, criado em 16 de julho de 1852, que está situado a $15 \mathrm{~km}$ do centro de Curitiba, estrategicamente cortado pela BR-277 e pela BR-376. Possui, na atualidade, 227.994 habitantes e é formada por descendentes de índios e de imigrantes predominantemente portugueses e espanhóis. Possui atualmente cerca de 4.000 servidores, também localizados em diferentes sedes. 


\subsection{RELACIONAMENTO ENTRE AS VARIÁVEIS DA NOVA GESTÃO PÚBLICA E AS VARIÁVEIS CULTURAIS}

O relacionamento entre as variáveis da nova gestão pública e as culturais, percebido nos estudos em questão, reitera a importância desse monitoramento cultural. As relações foram realizadas com base no protocolo de análise.

a) Reestruturação

A variável reestruturação, percebida nas Prefeituras, por meio da descentralização, do alinhamento e da reengenharia, mostra-se relacionada diretamente às variáveis poder e determinismo e, indiretamente, à variável personalismo.

\section{a.1) Descentralização}

Percebe-se, nas Prefeituras pesquisadas, uma grande concentração de poder, calcada na hierarquia e autoridade, o que faz com que a resolução de problemas, 0 atendimento a exceções, a adaptações e à inclusão de novos processos seja extremamente centralizada. Dessa forma, o processo de descentralização pode ser comprometido, visto que, para que ele ocorra, é necessário romper a estrutura hierárquica existente atualmente. Nesse sentido, observa-se que, na medida em que a Prefeitura se flexibiliza, como é o caso da Prefeitura 3, minimizando o formalismo e a autoridade, conseqüentemente dá-se a descentralização de tarefas, de responsabilidade e de poder. De forma contrária, nas Prefeituras 1 e 2, verifica-se uma forte estrutura hierárquica e autoritária, e, por conseguinte, o processo de descentralização encontra dificuldades de se efetivar.

Paralelamente, a variável determinismo, por meio da acomodação dos servidores, faz com que esses mantenham-se conformados e submissos à estrutura, não a questionando. Isso se faz perceber nas três Prefeituras, onde normalmente não se burlam regras e se encaminham exceções diretamente aos superiores. Na Prefeitura 1, os servidores mostram-se indiferentes às alterações que venham a ocorrer nas Prefeituras. Entretanto, nas Prefeituras 2 e 3, os servidores mostram-se incomodados com possíveis flexibilizações. Essa postura compromete o processo de reestruturação das Prefeituras. $\mathrm{Da}$ mesma forma, a percepção da variável personalismo, pela existência de privilégios nas Prefeituras, variável que é verificada em todas as Prefeituras, seja na forma de nomeações ou de contratações, pode dificultar a descentralização de ações, já que muitos servidores podem perder seus "padrinhos". Outro ponto importante no processo de descentralização é que esta gera uma desconcentração de cargos e funções, o que pode provocar, novamente, o rompimento da estrutura pessoal instaurada.

\section{a.2) Realinhamento}

O realinhamento das Prefeituras passa, necessariamente, pela adequação dos processos às constantes e novas necessidades da sociedade.

Para que isso ocorra, há que se flexibilizar a Prefeitura, permitindo uma rápida adequação às mudanças. Assim, a variável cultural adaptabilidade é fundamental para o sucesso do realinhamento da Prefeitura. Ao mesmo tempo, o rompimento com o formalismo e a hierarquia tornam-se pré-requisito para a implementação efetiva do realinhamento. Nesse sentido, comprova-se, nas Prefeituras 1 e 2, a sinalização da capacidade de atendimento às demandas, com base na agilidade de alterar seus processos. Na Prefeitura 3 é percebido também o rompimento do formalismo, sendo que nem sempre as regras são cumpridas. Em conseqüência, os processos não esbarram na hierarquia, o que permite um atendimento mais rápido e um realinhamento às demandas. 
No caso da Prefeitura 2, constata-se uma rigidez organizacional muito mais forte, acompanhada de uma forte centralização, o que gera um retardo no andamento e na adequação dos processos. Verifica-se, também, uma insegurança frente a possível flexibilização, como se dá nas três Prefeituras, o que pode comprometer o realinhamento, por meio de uma acomodação frente à necessidade de mudança.

\section{a.3) Reengenharia}

A recriação dos processos nas Prefeituras está diretamente relacionada com a variável poder, através da possibilidade da quebra do formalismo e da autoridade existente nas Prefeituras. Nesse sentido, comprova-se, nas três Prefeituras, a amarração hierárquica por meio da revisão e alterações processuais, sendo que nas Prefeituras 2 e 3, existe inclusive uma Controladoria Geral que tem essa função. A recriação dos processos pode eliminar funções que estão amarradas pelo clientelismo nas Prefeituras. Da mesma forma, esses novos processos podem dificultar a existência do patrimonialismo. Desse modo, a variável personalismo pode comprometer a condução da reengenharia nas Prefeituras. A amarração de cargos e contratações, com base em interesses pessoais, é percebida em todas as Prefeituras pesquisadas.

A possibilidade de desmantelar a estrutura das Prefeituras e a criação de novas formas de operação, relaciona-se diretamente com a variável determinismo e adaptabilidade, sendo que, no primeiro caso, pode surgir uma reação contrária às alterações, em função da acomodação das Prefeituras, e, no segundo caso, a capacidade das Prefeituras de se adaptar pode ajudar no processo de reengenharia. Comprova-se, nas Prefeituras pesquisadas, tanto o comportamento determinístico como a pré-disposição à adaptação.

\section{b) Práticas privadas}

As práticas privadas, que compõem a nova gestão pública, também têm como objetivo Modificar a forma de gestão das organizações públicas. Desse modo, a gestão pública que se relaciona com as variáveis culturais, é influenciada pelas práticas privadas.

\section{b.1) Foco no cliente}

Uma mudança significativa na dinâmica do poder público municipal requer que as Prefeituras adotem uma postura flexível, aberta à participação democrática dos cidadãos. Nesse sentido, o foco no cliente pode ser comprometido por três variáveis: o determinismo, o formalismo e o personalismo. 0 determinismo que gera acomodação, descomprometimento dos servidores para com 0 atendimento; 0 formalismo, que dificulta o acesso à informação e faz com que os processos esbarrem nas estruturas hierárquicas, e o personalismo, que direciona as ações, conforme 0 interesse dos cidadãos. As três Prefeituras pesquisadas demonstraram interesse em se adequarem para melhor atender às demandas sociais, principalmente a Prefeitura 2 que, segundo o gestor, busca focar-se nos interesses da comunidade.

\section{b.2) Tecnologia da informação}

Partindo do princípio que a tecnologia da informação dissemina as informações, descentralizando-as, essa pode ter relação direta com a autoridade e hierarquia, rompendo também alguns formalismos existentes nas Prefeituras. A tecnologia da informação é responsável pela transparência das Prefeituras. Ela tem a capacidade de eliminar atividades, gerando uma 
reorganização da Prefeitura. Dessa forma, ela tem chances de impactar profundamente a estrutura das Prefeituras, relacionando-se com as variáveis poder, personalismo e determinismo. Vale ressaltar que a variável adaptação colabora na introdução da tecnologia da informação, permitindo uma maior exploração da mesma.

Nas Prefeituras 2 e 3 a tecnologia foi considerada uma ferramenta que não compromete 0 poder das pessoas. Entretanto, ela tem a possibilidade de mexer com a estrutura das Prefeituras, o que é visto, por estas, como sinal de insegurança. Na Prefeitura 1, essa variável não foi analisada, devido a uma deficiência da ferramenta de coleta de dados do projeto piloto.

\section{b.3) Planejamento estratégico}

O planejamento estratégico pode ser afetado, principalmente, pela variável determinismo, já que ele trata de uma visão de longo prazo, que se contradiz com a postura de acomodação. Da mesma forma, no processo de planejamento estratégico também é possível identificar muitos problemas das Prefeituras - pontos fracos - que terão de ser ajustados, esbarrando, assim, nos formalismos e no personalismo existente nas Prefeituras. A percepção desses pontos fracos pode destacar ineficiências processuais e profissionais.

Nesse sentido, as Prefeituras 2 e 3 sentem-se inseguras quanto a possível alteração das regras existentes. No entanto, buscam introduzir o planejamento na Prefeitura. Na Prefeitura 1, essa variável não foi analisada, devido a uma deficiência da ferramenta de coleta de dados do projeto piloto.

\section{b.4) Administração por resultados}

A implementação da administração por resultados é afetada diretamente pela variável personalismo, já que os processos de nomeações, promoções, contratações, com base no clientelismo e patrimonialismo, divergem do método de avaliação por resultados. Verifica-se, nesse sentido, nas três Prefeituras, a existência do personalismo contrastando com a busca pela profissionalização. A administração por resultados, com enfoque nos objetivos macros, pode ser também impactada pela variável determinismo e pela acomodação dos servidores no momento de tomar uma ação, o que dificulta 0 andamento dos processos e 0 conseqüente alcance dos objetivos. A variável poder, tendo em vista o formalismo que concentra a avaliação nas bases de regras, nos procedimentos e não no efetivo resultado das ações, pode dificultar a administração por resultados, já que esta não considera as normas e procedimentos. A falta de delegação de poder e decisões distanciam os executores da realidade, dificultando a avaliação dos resultados.

Percebe-se que a Prefeitura 2 apresenta dificuldades no atendimento às demandas da sociedade, o qual representa o objetivo final dessa instituição. Ela não se mostra ágil na adequação dos processos, podendo ter sido influenciada pela estrutura formal e hierarquizada. A maior flexibilização, percebida nas Prefeituras 1 e 3, pode ser responsável pela aproximação delas no que tange ao atendimento das demandas de suas cidades. Comprova-se, dessa forma, na Prefeitura 3, a descentralização de poder, em níveis mais próximos, como diretores de seção, tornando a Prefeitura mais ágil e efetiva.

\section{b.5) Empreendedorismo}

A variável empreendedorismo e a capacidade de adaptação são percebidas nas três Prefeituras, por meio do incentivo à criatividade e à iniciativa dos servidores. Contudo, 0 empreendedorismo propõe uma maior flexibilidade e atitude dos servidores, que podem ser impedidas pela acomodação existente. Nas três Prefeituras denota-se a dificuldade de as pessoas trabalharem 
por si só, sempre existindo a dependência hierárquica. 0 empreendedorismo, por sua vez, prega uma organização flexível e criativa, em que as idéias são fundamentais, e deve ser implementado. 0 risco é gerar a quebra do formalismo existente na Prefeitura.

Nas Prefeituras 2 e 3, verifica-se que as idéias são ouvidas, mas não implementadas em função das regras pré-estabelecidas. A flexibilização empreendedora transforma a estrutura da Prefeitura de vertical para horizontal, chocando-se, assim, com a hierarquia e autoridade. Essas duas relacionam-se com a variável poder nas Prefeituras.

Nessa direção, nas três Prefeituras, comprova-se a dificuldade de implementação das sugestões e idéias, em função da estrutura de cada Prefeitura. De maneira paralela, 0 empreendedorismo trabalha sob a base da competência pessoal. Ele abre chances de gerar um conflito direto com a cultura clientelista e patrimonialista das nomeações e contratações, que se dão com base em privilégios existentes nas três Prefeituras.

c) Participação Social

A participação social foi verificada nas Prefeituras, considerando a abertura à sociedade, bem como pela pré-disposição à transparência frente aos cidadãos.

\section{c.1) Abertura à sociedade}

No contexto da nova gestão pública, a atuação social funciona como um complemento, ou seja, a comunidade deve participar ativamente do processo. Esse processo consiste no compartilhamento de informações e ações com a sociedade civil, permitindo que esta realize o controle do Estado. Assim, esse novo formato de participação social pode esbarrar diretamente com a autoridade e com 0 formalismo, os quais podem comprometer a abertura das Prefeituras à participação social.

Em contraponto à variável determinismo, a participação social ativa demanda uma flexibilização das Prefeituras. Demanda, também, uma postura de cooperação, que se opõe à postura determinística encontrada nas Prefeituras. Com a presente pesquisa, verifica-se que os servidores das Prefeituras 2 e 3 mostram-se receosos à flexibilização das regras, em função da tendência à acomodação. No entanto, a participação da sociedade aparece nesse cenário como um avanço administrativo.

A variável personalismo tanto pode produzir impacto sobre o processo de participação social, como ocorreu no passado, com as tentativas de reforma do Estado, quanto pode gerar uma resistência organizacional baseada no patrimonialismo e no clientelismo, como vem ocorrendo nas Prefeituras estudadas.

\section{CONCLUSÃO}

O novo cenário mundial, caracterizado por constantes e rápidas mudanças, tem alterado, de forma direta, a dinâmica existente nos municípios. Em particular, no Brasil, pode-se afirmar que até 1995 os municípios eram geridos por meio das decisões de âmbito federal, sendo que para eles eram repassadas atividades, em sua maioria, operacionais. Esse cenário tem demandado a construção de uma série de novos conceitos e práticas para que os municípios consigam sobreviver frente aos novos desafios. A nova gestão pública propõe um novo formato de gestão, possibilitando uma adequação da máquina administrativa estatal as suas novas demandas e, conseqüentemente, uma melhoria efetiva 
do Estado. Nesse processo de mudança de gestão, o Estado tem buscado, nas experiências das organizações privadas, novos formatos de gestão.

As experiências de reformas administrativas dos Estados, no mundo, têm demonstrado que, do ponto de vista de gestão, o caminho é esse. Entretanto, existem barreiras quanto à implementação efetiva das novas práticas. Nesse sentido, já no plano de reforma do Estado de 1995, observava-se a necessidade de uma dedicação especial às questões institucionais legais e culturais, visto que 0 sucesso da implementação de novas práticas nas organizações públicas ou privadas pode ser influenciado pelos traços culturais existentes nas organizações públicas. Assim, fica visível que, em específico, no caso das prefeituras brasileiras, existem variáveis culturais que podem impactar no sucesso das reformas administrativas necessárias.

A pesquisa teve como objetivo a análise da existência de variáveis culturais brasileiras nas prefeituras, que podem influenciar a nova gestão pública. A identificação e o relacionamento das variáveis selecionadas permitiram a percepção de que as Prefeituras apresentam, em suas estruturas, as variáveis referenciadas da cultura brasileira (poder, personalismo, determinismo e adaptabilidade) e essas variáveis relacionam-se diretamente com a nova gestão pública. 0 relacionamento, em geral, faz referência à contradição entre a nova cultura e a cultura existente nas Prefeituras, com exceção à variável adaptabilidade que vai ao encontro da proposta da nova gestão pública.

A pesquisa partiu de um aprofundamento teórico sobre as temáticas da nova gestão pública e cultura, permitindo a identificação das principais variáveis de ambas. Foram selecionadas as variáveis culturais - poder, personalismo, determinismo e adaptabilidade - e as variáveis da nova gestão pública a reestruturação organizacional, foco no cliente, tecnologia da informação, planejamento estratégico, administração de resultados, empreendedorismo, participação social, parceria público-privado. A pesquisa foi realizada por meio de um estudo de multicasos, abrangendo três Prefeituras. Foi feita uma triangulação das ferramentas de coleta de dados (questionários, entrevistas e observações), o que permitiu 0 aprofundamento das análises, com base no protocolo de pesquisa elaborado. Através do cruzamento dos dados oriundos das várias ferramentas de coleta de dados, pode-se constatar que as variáveis culturais selecionadas encontram-se presentes nas Prefeituras e estão relacionadas aos processos da nova gestão pública.

A presença da variável "poder" pode indicar dificuldades à nova gestão pública, já que, quanto maior a percepção do poder na Prefeitura, mais difícil é o processo de reestruturação dela e maior é a probabilidade de empecilhos à introdução de práticas privadas. 0 poder pode gerar uma resistência à participação social, principalmente no que diz respeito à transparência e ao controle dos processos das Prefeituras por parte da sociedade.

A variável "personalismo", que pode comprometer a reestruturação das Prefeituras, passa pela revisão de cargos e funções, que atualmente é fortemente influenciada pelas relações pessoais. Da mesma forma, essa variável pode afetar a introdução das práticas privadas, sendo que estas também entram em conflito com a cultura de privilégios existente nas organizações. A variável pode, ainda, comprometer a participação social, principalmente pela tentativa de manutenção da cultura desses privilégios.

A variável "determinismo" pode dificultar o processo de alinhamento das Prefeituras, comprometendo o processo de reestruturação da prefeitura e a conseqüente impossibilidade de implantação das práticas privadas. 0 determinismo pode também afetar o processo de participação social pela falta de comprometimento dos servidores com a efetividade das ações e a importância da sociedade nesse processo.

A variável "adaptabilidade" pode colaborar com a nova gestão pública. Quanto maior a variável adaptabilidade da Prefeitura, maior a potencialidade desta para a reestruturação, para a implementação das práticas privadas e para a participação social.

Nesse sentido, percebe-se que a Prefeitura 2 pode ser considerada a que possui as variáveis culturais mais fortemente arraigadas. Ela pode ser compreendida como aquela que tem mais 
dificuldades em implementar a nova gestão pública, em função da relevância das variáveis culturais. A Prefeitura 3 pode ser considerada a que possui uma maior evolução no sentido de minimizar ou potencializar algumas variáveis e pode ser a que apresenta mais avanços na nova gestão pública. $\mathrm{A}$ Prefeitura 1 pode ser caracterizada como intermediária, já que os resultados sinalizam uma menor concentração das variáveis culturais que a Prefeitura 2, conseqüentemente uma maior facilidade quanto à introdução dos preceitos da nova gestão pública.

Merece destaque a variável "poder", presente nas Prefeituras estudadas, visto que essa variável encontra-se atrelada às outras variáveis e assim pode ser considerada a mais importante no processo da nova gestão pública. $O$ tratamento dessa variável poderá permitir um grande avanço na reestruturação da gestão municipal.

O conhecimento e a conscientização da existência e da importância da cultura organizacional poderão permitir aos gestores um melhor posicionamento frente à gestão da Prefeitura, bem como a descoberta dos motivos do insucesso de algumas iniciativas, que porventura esbarrem na cultura organizacional existente.

A conscientização da existência de uma estrutura cultural, baseada na variável "poder", possibilita uma reavaliação dos modelos institucionais nas Prefeituras, permitindo a melhoria administrativa. A percepção do relacionamento entre a variável "determinismo" e "poder" permite uma concentração de esforços, de forma a efetivar as iniciativas existentes de flexibilização e criatividade. Da mesma forma, a constatação da existência da variável "personalismo" nas Prefeituras possibilita 0 reforço da real função do Estado. Essa conscientização é de extrema importância, já que nem todos nas Prefeituras percebem ou aceitam a existência dessas variáveis. Se as variáveis não existem e não são consideradas, pode acarretar o desperdício de tempo e de dinheiro na implementação da nova gestão pública. Com o conhecimento e a devida consideração das variáveis no processo de mudança é possível garantir uma atuação mais compromissada e democrática, minimizando-se os ranços culturais.

A pesquisa possibilita a percepção dos acadêmicos de gestão urbana na relevância da temática cultural, dando destaque ao relacionamento das variáveis culturais identificadas com as várias áreas temáticas estudadas na gestão urbana. É possível estabelecer relações teóricas e práticas entre os resultados das várias experiências de mudanças administrativas implementadas nas Prefeituras, bem como estabelecer novas hipóteses sobre modelos de intervenção à gestão dos municípios, usando 0 conhecimento da presença das variáveis identificadas. Esta pesquisa também abre espaço para 0 aprofundamento de pesquisas multidisciplinares, envolvendo as variáveis identificadas na análise das práticas utilizadas na gestão urbana, permitindo uma melhor compreensão do fenômeno urbano.

O contexto onde os municípios estão inseridos exige deles uma grande mudança na forma de condução de suas atividades. Essa mudança perpassa todas as áreas acadêmicas e práticas. Os municípios vivem atualmente em um cenário em constantes transformações, desde as administrativas até as operacionais. $O$ desafio vivenciado pelos municípios faz com que seja necessário um esforço em todas as áreas, de forma simultânea.

Desse modo, percebe-se um grande esforço em pesquisas, analisando-se as mais diversas adequações necessárias ao novo cenário citadino. Trata-se de uma revisão geral de conceitos, em que a gestão urbana assume uma dimensão maior. A forma de pensar e agir do e sobre 0 urbano muda. Questiona-se a forma de ver o urbano, de gerir o urbano, de planejar o urbano, de sustentar o urbano. Questiona-se, sobretudo, a cultura do urbano e é esta que permitirá 0 alcance das alterações conceituais necessárias. É por meio da evolução cultural que será possível concretizar os estudos relativos à gestão urbana.

Para que isso ocorra, é necessária uma auto-análise cultural da cidade, Prefeitura, comunidade, enfim, de todos os atores envolvidos com a gestão urbana, e a ponderação sobre essa auto-análise. O desafio da gestão urbana é a mudança cultural de um formato de gestão 
institucionalizada, que deve ser encarada dessa maneira, sendo que todas as intervenções realizadas na gestão pública devem considerar as necessidades de adequação ou a gestão da cultura envolvida.

\section{REFERÊNCIAS}

AIDAR, M. M. et al Cultura organizacional brasileira. In WOOD, T. Mudança organizacional: aprofundando temas atuais em administração de empresas. 2 ed. São Paulo: Atlas, 2002. p. 34-58.

AMATO, P. M. Introdução à administração pública. 2 ed. Rio de Janeiro: FGV, 1971.

BARBOSA, L. Meritocracia à brasileira: o que é desempenho no Brasil?. Revista do Serviço Público. Brasília, ano 47, v. 120, n. 3, set-dez. 1996.

BARBOSA, L. 0 jeitinho brasileiro. Rio de Janeiro: Elsevier, 1992.

BARREIRA, I. A. F, A. cidade no fluxo do tempo: invenção do passado e patrimônio. Sociologias. Porto Alegre, ano 5, n. 9, p. 314-339, jan/jun, 2003.

BARROS, B. T.; PRATES, M. A. S. O estilo brasileiro de administrar. São Paulo: Atlas, 1996.

BRASIL. Plano Diretor da Reforma do Aparelho do Estado. Brasília: Presidência da República, Imprensa Nacional, novembro 1995.

CASTELLS, M. A sociedade em rede. A era da informação: economia, sociedade e cultura. v. 1. São Paulo: Paz e Terra, 1999.

CLEGG, S. Poder, linguagem e ação nas organizações. CHANLAT, J. F. O indivíduo na organização: dimensões esquecidas. São Paulo: Atlas, 1992, v.2.

DA' MATTA, R. Carnavais, malandros e heróis: para uma sociologia do dilema brasileiro. 6 ed., Rio de Janeiro: Rocco, 1997.

DOWBOR, L. O poder local diante dos novos desafios sociais. In: FUNDAÇÃO PREFEITO FARIA CEPAM. O município no século XXI: cenários e perspectivas. Ed. Especial. São Paulo: CEPAM, 1999.

DRUCKER, P. Administrando em tempos de grandes mudanças. São Paulo: Pioneira, 1999.

FAORO, R. Os donos do poder: formação do patronato político brasileiro. v. 1.10 ed., São Paulo: Globo: Publifolha, 2000.

FERGUSON, M. Estratégias de governo eletrônico: O cenário internacional em desenvolvimento. In: EINSNBERG, J. CEPIK, M. Internet e política: teoria e prática da democracia eletrônica. Belo Horizonte: Editora UFMG, 2002.

FLEURY, M. T. L. Arqueologia Teórica e dilemas metodológicos dos estudos sobre cultura organizacional. In MOTTA, F. C. P.; CALDAS, M. P.; Cultura Organizacional e Cultura Brasileira. São Paulo, Atlas, 1997, cap. 16, p. 273-292.

FREITAS, M. E. Cultura organizacional: formação, tipologia e impactos. São Paulo: Makron MacGraw-Hill, 1991.

GEERTZ, C. A interpretação das culturas. Rio de Janeiro: Zahar, 1978.

GIL, A. C. Métodos e técnicas de pesquisa social. 5 ed. São Paulo: Atlas, 1999. 
GILBERT J., Cultural complexity in organizations. Journal of Occupational and Organizational Psychology. Leicester, v. 75, n. 2, p. 251 jun, 2002.

GOHN, M. G. Educação não formal e cultura política: impactos sobre o associativismo do terceiro setor. 2. ed. São Paulo: Cortez, 2001.

HERNANDEZ, J. M. C.; CALDAS, M. P. Resistência à mudança: uma revisão crítica. Revista de Administração de empresas. São Paulo, v. 41, n. 2, p. 31-45, abr./jun., 2001.

HOFSTEDE, G. A cultura da empresa. Correio UNESCO, ano 22, n. 6 p. 8-12, jun.1994.

JONES, L. R.; THOMPSON, F. Um modelo para a nova gerência pública. Revista do Serviço Público. Brasília, ano 51, n. 1, jan / mar 2002.

KOHN, L. T. Methods in case study analysis. Center for studying system change. Technical Publication, n. 2, jun. 1997.

LARAIA, R. B. Cultura: um conceito antropológico. 16. ed. Rio de Janeiro: Zahar, 2003.

LOPES, R. A cidade intencional: o planejamento estratégico de cidades. Rio de janeiro: Mauad, 1998.

MARCONI, M. A. LAKATOS, E. M. Técnicas de pesquisa: planejamento e execução de pesquisas, amostragem e técnicas de pesquisa, elaboração, análise e interpretação de dados. 2. ed. São Paulo: Atlas, 1990.

MARINI, C. O contexto contemporâneo da administração pública na América Latina. Revista do Serviço Público. Brasília, ano 53, n. 4, out./dez./ 2002.

NELSON, R. E.; LOUREIRO, M. C. Cultura Organizacional: vencendo o dragão da resistência. Rio de Janeiro: Imagem, 1996.

OSBORNE, D.; GLAEBLER, T. Reinventando o governo: como o espírito empreendedor está transformando o setor público. Brasília: MH Comunicação, 1998.

PEREIRA, L. C. B. Estratégia e estrutura para um novo Estado. Revista do Serviço Público. Brasília, ano 48, n. 1, jan.-abr. 1997.

PFEIFFER, P. Planejamento estratégico municipal no Brasil: uma nova abordagem. Textos para discussão 32. Brasília: ENAP, 2000.

REZENDE, D. A. Planejamento Estratégico Municipal e sua Relação com as Políticas de Gestão de Cidades e com a Teoria Nova gestão pública. In: Encontro de Administração Pública e Governança da ANPAD, 1., 2004, Rio de Janeiro. Anais... Rio de Janeiro: EnAPG, 2004.

REZENDE, D. A.; CASTOR, B. V. J. Planejamento estratégico municipal: empreendedorismo participativo nas cidades, Prefeituras e organizações públicas. Rio de Janeiro: Brasport, 2005.

ROESCH, S. M. A. Projeto de estágio e de pesquisa em administração: guia para estágios, trabalhos de conclusão, dissertação e estudos de caso. 2. ed. São Paulo: Atlas, 1999.

SCHEIN, E. H. Organizational Culture and leadership. Jossey-Bass Plublishers. San Francisco: Oxford, 1990.

YIN, R. K. Case study research. London: Sage Pub, 1994. 


\section{ANALYSIS OF THE CULTURAL VARIABLES OF THE MUNICIPAL ADMINISTRATION UNDER THE OPTICAL OF THE NEW PUBLIC MANAGEMENT}

The new municipal management is based in the introduction of management practices from the private management in the mayor halls (Prefectures), searching for a better effectiveness in its actions. The main objective of this research is to analyze which cultural variables in the mayor halls can influence the management relates to the concepts of the new public management. Based in bibliographical research were notice cultural variables (such as: power, personalism, determinism and adaptability) from the new public management (re-structure, private practices and social participation), that direct the research protocol. Through a multi-case study, in three mayor halls of the metropolitan region of Curitiba and with the comparison of the tools of collecting data tools used (questionnaire, interviews, and systematic observation) it was possible to identify of cultural variables in the mayor halls and the deepening of the existent relationships among them. The conclusion reiterates the identification and construction of a cultural variables map could enable the municipal managers a better control and utilization in their actions.

Key words: Municipal managemet. Brazilian culture. Organizational culture.

Data de Submissão: agosto de 2006 Data de Aceite: maio de 2007 